\title{
Bioavailability and nutritional effects of carotenoids from organically and conventionally produced carrots in healthy men
}

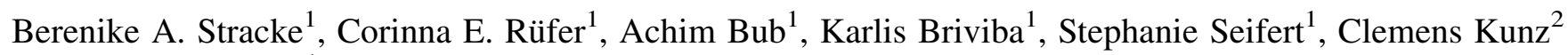 \\ and Bernhard Watzl ${ }^{1 *}$ \\ ${ }^{1}$ Institute of Physiology and Biochemistry of Nutrition, Max Rubner-Institut, Federal Research Institute of Nutrition and Food, \\ Haid- und Neu-straße 9, 76131 Karlsruhe, Germany \\ ${ }^{2}$ Institute of Nutritional Sciences, Justus-Liebig-University Giessen, Wilhelmstraße 20, 35392 Giessen, Germany
}

(Received 4 June 2008 - Revised 11 September 2008 - Accepted 12 September 2008 - First published online 20 November 2008)

It has been hypothesised that organically grown vegetables are healthier than conventionally produced ones due to a higher content of phytochemicals. However, few data from controlled human studies exist. The aim of the present study was to compare the carotenoid content and antioxidant capacity of organically and conventionally produced carrots under defined conditions. Furthermore, a human intervention study was conducted to compare bioavailability, plasma antioxidant capacity, endogenous DNA strand breaks and immune parameters in healthy men ingesting carrots from different agricultural systems. Thirty-six volunteers consumed either organically or conventionally produced blanched carrots $(200 \mathrm{~g} / \mathrm{d}$; 2 weeks) or no carrots in a double-blind, randomised intervention study. No statistically significant differences were observed in the total carotenoid contents (121 (SD 7) $\mu \mathrm{g} / \mathrm{g}$ organic $v .116$ (SD 13) $\mu \mathrm{g} / \mathrm{g}$ conventional) and the antioxidant capacities (0.43 (SD 0.08) $\mu$ mol Trolox equivalents/g organic $v$. 0.32 (SD 0.07$) \mu \mathrm{mol}$ Trolox equivalents/g conventional) of the carrots administered to the volunteers. Intake of organically or conventionally produced carrots significantly increased $(P<0.001)$ plasma $\alpha$ - and $\beta$-carotene concentrations in both intervention groups without differences in plasma carotenoid concentrations. Consumption of carrots did not lead to significant changes in the plasma antioxidant status, endogenous DNA strand breaks and parameters of the immune system in all groups. Therefore, these results indicate that the agricultural system has neither an effect on the carotenoid content, the antioxidant capacity of carrots, nor on the bioavailability of carotenoids and on antioxidant, antigenotoxic and immunological effects as assessed in a human intervention study.

Organic food: Carotenoids: Bioavailability: Antioxidant status

Since 1990 organic food sales have been increasing by $20 \%$ per year in Europe and North America ${ }^{(1)}$. Consumer studies suggest multiple reasons for buying organic fruits and vegetables, for example, they taste better, are healthier and safer ${ }^{(2)}$. It has been shown that organic fruits and vegetables have a lower content of pesticides than conventionally produced foods. Furthermore, it has been hypothesised that organically grown fruits and vegetables could be healthier due to a higher content of phytochemicals (for example, carotenoids $)^{(3-8)}$.

Several studies have been conducted to gain information about the impact of the agricultural system on carotenoids. A higher carotenoid content was found in organically grown sweet peppers, tomatoes, yellow plums, carrots, celery and $\mathrm{kale}^{(4-8)}$. In contrast a lower content was found in organically produced carrots, tomatoes and grapefruits ${ }^{(9-11)}$. No differences in carrots, cabbage, leek, potatoes, spinach and lettuce were determined in an older study ${ }^{(12)}$. These inconsistencies suggest that factors other than the organic production method might affect carotenoid content, for example, the cultivar, the microclimate, the degree of ripeness and the soil conditions. Several of the conducted studies did not take these factors into account ${ }^{(5,13,14)}$. Therefore, the results are inconclusive. Obviously, there is a need for more studies comparing the carotenoid content of fruits and vegetables under well-controlled conditions.

To date, only one human intervention study has been conducted to compare the bioavailability of carotenoids from organically $v$. conventionally produced tomato purée in human subjects ${ }^{(5)}$. In this study, no differences between the bioavailability of lycopene and $\beta$-carotene from organically $v$. conventionally produced tomato purée were observed. Additionally, there were no significant differences in polyphenol and vitamin $\mathrm{C}$ concentrations between the two groups ${ }^{(5)}$.

Further human intervention studies were conducted to investigate the bioavailability of phenolic compounds from a diet based on organic food, red wine and apples ${ }^{(15-18)}$. A diet based on organically produced food (meat, potato, wheat, rye, fruits, vegetables) resulted in a higher urinary excretion of quercetin and kaempherol, increased protein

Abbreviations: ABTS, 2,2'-azino-bis(3-ethylbenzothiazoline-6-sulfonic acid) diammonium salt; FRAP, ferric-reducing ability of plasma; NK, natural killer; ORAC, oxygen radical absorbance capacity; PBMC, peripheral blood mononuclear cells; TEAC, Trolox equivalent antioxidative capacity.

* Corresponding author: Dr Bernhard Watzl, fax +49 7216625 404, email bernhard.watzl@mri.bund.de 
oxidation and decreased plasma antioxidant capacity in the group that ate organically produced food ${ }^{(15)}$. The plasma antioxidant capacity in the subjects receiving a diet based on organically produced food was higher than by a diet based on conventionally produced food ${ }^{(16)}$. In humans the ingestion of conventionally produced red wine led to a decrease in $\mathrm{Cu}^{2+}$ induced formation of thiobarbituric acid-reactive substances. In contrast, the consumption of organically produced red wine increased the catalase activity in erythrocytes ${ }^{(17)}$. Consumption of organic or conventional apples $(1 \mathrm{~kg})$ showed no effect on the antioxidant capacity of LDL (lag-time test), endogenous DNA strand breaks, Fpg protein-sensitive sites or capacity to protect DNA against damage caused by $\mathrm{H}_{2} \mathrm{O}_{2}$. However, $24 \mathrm{~h}$ after apple consumption in both intervention groups, decreased levels of endonuclease III-sensitive sites and an increased capacity to protect DNA against damage induced by iron chloride were observed ${ }^{(18)}$. Studies have shown that carotenoids positively affect the antioxidant capacity and the immune system in humans ${ }^{(19)}$.

There are no data on whether the agricultural system affects the bioavailability of carotenoids and physiological effects after the consumption of organically and conventionally produced carrots. It has been shown that the bioavailability of carotenoids may be affected by the food matrix. Organically produced carrots generally have a higher DM content than conventionally produced ones ${ }^{(20,21)}$; this could result from different food matrices. So, one might speculate that the agricultural system affects the bioavailability of carotenoids from carrots.

Therefore, the aim of the present study was to evaluate the carotenoid content and the antioxidant capacity of carrots grown in Northern Germany under either defined organic or conventional agricultural conditions. Furthermore, we investigated whether the agricultural farming system influences carotenoid bioavailability, antioxidant status and the immune system in healthy young men after the consumption of blanched carrots.

\section{Materials and methods}

\section{Chemicals}

All chemicals were purchased from Carl Roth (Karlsruhe, Germany), Sigma-Aldrich (Taufkirchen, Germany) or Merck (Darmstadt, Germany).

\section{Carrot samples}

Carrots (Daucus carota ssp. sativus, variety Narbonne) were harvested in 2005 from two farms in Schleswig-Holstein, County Dithmarschen, Germany. Carrots from organic and conventional farming systems were used. The distance between the organic and conventional fields averaged $3 \mathrm{~km}$. The fertilisation, harvest and distribution of the carrots were monitored by the Institute of Organic Farming of the Johann Heinrich von Thünen-Institute, Federal Research Institute for Rural Areas, Forestry and Fisheries at Westerau. Soil and microclimate conditions were comparable. After harvest the carrot samples were stored at $0.4-4^{\circ} \mathrm{C}$ and $98 \%$ humidity for 2 weeks. For the human intervention study the carrots were sliced and blanched using a steamer (Konvektomat type E-HD 1011 P; Imperial, Bünde, Germany) for $3 \mathrm{~min}$ at $110^{\circ} \mathrm{C}$. Thereafter, the carrots were packed in $200 \mathrm{~g}$ portions and stored at $-30^{\circ} \mathrm{C}$ until use.

\section{Subjects}

Thirty-six non-smoking men, aged between 19 and 54 years were recruited. The subjects were healthy according to clinical examination and disease history. They refrained from taking vitamin supplements or any medication for 6 months before and during the study. The study was approved by the Landesärztekammer Baden-Württemberg and all participants gave their written consent.

\section{Study design}

The study was a randomised, controlled, double-blind trial of 6-week duration. Study participants were allocated to three groups (n 12 per group). Intervention was preceded by a 4-week low-carotenoid period where subjects were asked to refrain from foods rich in carotenoids (for example, carrots, carrot products, lettuce and spinach). Intervention lasted from day 0 to day 14 . During the intervention period the volunteers of the intervention groups consumed daily $200 \mathrm{~g}$ blanched carrots from organic or conventional agricultural systems for 2 weeks. Subjects were told to consume the carrots with a main meal and with a minimum of $10 \mathrm{~g}$ fat. The third group was a control group who maintained a carotenoid-restricted diet throughout the total study period of 6 weeks.

\section{Collection and preparation of blood samples}

Fasting blood samples were taken in the morning before carrot intake between 07.00 and 10.00 hours at day 0 as well as on days 2, 7 and 14 of the intervention period. Blood was drawn from an antecubital vein into prechilled tubes containing EDTA (1.6 g/l, Monovette; Sarstedt AG \& Co., Nümbrecht, Germany) for carotenoid and antioxidant status and into lithium heparin tubes (Sarstedt) for immune parameters. Plasma was collected after centrifugation at $1500 \mathrm{~g}$ for $10 \mathrm{~min}$ at $4^{\circ} \mathrm{C}$. Tubes without anticoagulant (Serum-Monovette; Sarstedt AG $\&$ Co.) were used for serum collections. Blood was allowed to clot at room temperature for $30 \mathrm{~min}$ and was centrifuged at $1500 \mathrm{~g}$ for $10 \mathrm{~min}$ at room temperature. Serum was stored at $-30^{\circ} \mathrm{C}$ and plasma at $-80^{\circ} \mathrm{C}$ until analysis.

\section{Methods for analyses in carrots}

Carotenoid extraction from blanched carrots. Five grams of one $200 \mathrm{~g}$ portion of blanched carrots were homogenised using a laboratory blender (B400; Büchi Labortechnik AG, Flawil, Switzerland). Samples of $0.3 \mathrm{~g}$ were further homogenised in $50 \mu \mathrm{l} 100 \mathrm{~mm}$-EDTA and $5 \mathrm{ml}$ acetone containing $0.01 \%$ butylated hydroxytoluene using an Ultra Turrax T25 (IKA, Staufen, Germany). The homogenate was centrifuged at $3000 \mathrm{~g}$ for $5 \mathrm{~min}$ at $4^{\circ} \mathrm{C}$ and the organic extracts were collected in a separate tube. Extraction was repeated until the organic extracts were colourless. After washing the combined organic extracts with $5 \mathrm{ml}$ of a saturated $\mathrm{NaCl}$ solution the organic solvent was removed using a rotary evaporator (Laborota 4003-digital; Heidolph, Schwabach, Germany). The remaining aqueous phase was extracted three times with $2 \mathrm{ml} n$-hexane 
containing $0.01 \%$ butylated hydroxytoluene and the combined organic extracts were evaporated to dryness under a stream of $\mathrm{N}_{2}$ gas. For HPLC analysis the residue was dissolved in $200 \mu \mathrm{l}$ of acetone-dichloromethane $(10: 1, \mathrm{v} / \mathrm{v}, 0.01 \%$ butylated hydroxytoluene) and $50 \mu \mathrm{l}$ were used for HPLC analysis. In total, samples from five different $200 \mathrm{~g}$ portions were analysed.

Analysis of dry matter in carrots. About $5 \mathrm{~g}$ of the homogenates were dried for $5 \mathrm{~h}$ at $110^{\circ} \mathrm{C}$. The analysis was repeated five times.

High-performance liquid chromatography analysis. HPLC analysis was performed on a low-pressure gradient system from Shimadzu (Duisburg, Germany) equipped with an autoinjector, column oven and photodiode array detector. The autoinjector was set to $10^{\circ} \mathrm{C}$ and the column oven to $27^{\circ} \mathrm{C}$.

Separation was carried out on a $250 \times 4.6 \mathrm{~mm}$ internal diameter, $5 \mu \mathrm{m}$, YMC 'Carotenoid' S5 reversed-phase C30 column with a corresponding $10 \times 4.0 \mathrm{~mm}$ internal diameter guard column (YMC Europe GmbH, Dinslaken, Germany). Solvent A consisted of tert-butyl methyl ether, solvent B of methanol and solvent $\mathrm{C}$ of water. A linear gradient was used starting with $20 \% \mathrm{~A}, 60 \% \mathrm{~B}$ and $20 \% \mathrm{C}$ going to $80 \% \mathrm{~A}$, $20 \% \mathrm{~B}$ and $0 \% \mathrm{C}$ within $50 \mathrm{~min}$. The flow rate was $1 \mathrm{ml} / \mathrm{min}$ and the detection wavelength was set to $\lambda=450 \mathrm{~nm}$. Quantification was performed by external calibration using reference compounds. Calibration curves of different carotenoids were performed in the range of $0.025-25 \mathrm{mmol} / \mathrm{l}$, in which the linearity of the response was given. The recovery for all carotenoids was greater than $95 \%$. The $\mathrm{CV}$ of the method was below $5 \%$ (intra-assay).

Extraction of lipophilic antioxidants from carrots. Samples of $0.2 \mathrm{~g}$ of the homogenised carrots (see above) were further homogenised in $10 \mathrm{ml}$ acetone for $10 \mathrm{~min}$ in an ice-cold ultrasonic bath. The homogenate was centrifuged at $3000 \mathrm{~g}$ for $5 \mathrm{~min}$ at $4{ }^{\circ} \mathrm{C}$ and the supernatant fraction was collected. Extraction was repeated until the pellets were colourless. After washing the combined organic extracts twice with $5 \mathrm{ml} n$-hexane and $1 \mathrm{ml}$ saturated $\mathrm{NaCl}$ solution, the organic extracts were evaporated to dryness under a stream of $\mathrm{N}_{2}$ gas. The extracts were dissolved in $3 \mathrm{ml}$ acetone for analysis.

Antioxidant activity in lipophilic carrot extracts. To determine the lipophilic antioxidant activity in carrots the Trolox equivalent antioxidative capacity (TEAC) assay as described by $\operatorname{Re}$ et al. was used ${ }^{(22)}$. The reaction was carried out in ethanol; the final reaction mixture volume was $300 \mu l$. Trolox at $10,20,30$ and $50 \mu \mathrm{mol} / 1$ (used as standards), $100 \mu \mathrm{l}$ of carrot samples (in acetone) (see below) or acetone alone (blank) were added in ninety-six-well plates (Greiner, Frickenhausen, Germany). The 2,2'-azino-bis(3-ethxylbenzothiazoline-6-sulfonic acid) diammonium salt (ABTS) radical cation $\left(\mathrm{ABTS}^{+}\right.$) was formed by the reaction of a $7 \mathrm{~mm}-\mathrm{ABTS}$ stock solution with $2.45 \mathrm{mM}$-potassium persulfate (final concentrations) in the dark at room temperature for $12-16 \mathrm{~h}$ before use. The ABTS $^{-+}$solution was diluted with ethanol to an absorbance of 0.70 (SD 0.02$)$ at $734 \mathrm{~nm}$. The reaction mixture was started by the addition of $200 \mu \mathrm{l}$ prewarmed $\left(30^{\circ} \mathrm{C}\right)$ ABTS $^{+}$solution per well. The absorbance was measured after $2.5 \mathrm{~min}$ incubation at $30^{\circ} \mathrm{C}$ in a microplate reader (Tecan safire ${ }^{2}$; Tecan, Crailsheim, Germany). The microplate was shaken before each reading. The carrot extracts were diluted appropriately in acetone. All analyses were performed fourfold. The Trolox equivalent concentration of the carrots was calculated by subtracting the blank reading from samples and standards. A linear calibration curve for each assay was constructed. Intra- and inter-assay variations were always less than $5 \%$.

\section{Methods for analyses in blood samples}

Serum parameters. Glucose, TAG, cholesterol and uric acid were determined using enzymic kits (Boehringer Mannheim, Germany).

Carotenoids, vitamin $E$ and vitamin $C$ in plasma. Concentrations of carotenoids in plasma ( $\alpha$ - and $\beta$-carotene, lycopene, lutein, zeaxanthin and $\beta$-cryptoxanthin) and vitamin E ( $\alpha$-tocopherol) were determined according to the method described previously ${ }^{(23)}$. The same HPLC system as for the determination of carotenoids in carrots was used. The vitamin $\mathrm{C}$ concentration was determined as described earlier ${ }^{(24)}$.

Antioxidant activity in plasma. Total antioxidant status in plasma was analysed using the ferric-reducing ability of plasma (FRAP) ${ }^{(25)}$, the oxygen radical absorbance capacity $(\mathrm{ORAC})^{(26)}$ and the TEAC ${ }^{(2)}$ assays.

Low-density lipoprotein oxidation. An ultracentrifugation method was used to isolate LDL from plasma ${ }^{(27)}$. The ex vivo oxidation of LDL was performed using a modification of the procedure described by Esterbauer et al. ${ }^{(28)}$. The LDL concentration in the PBS solution was determined by measuring the protein concentration and was adjusted for the oxidation assay to $100 \mu \mathrm{g} / \mathrm{ml}$ protein. The LDL oxidation process was followed by determining the formation of conjugated dienes by measuring the absorption at $\lambda=234 \mathrm{~nm}$ in a microplate reader (Tecan safire ${ }^{2}$ ). The reaction was carried out in PBS (100 mmol/l; pH 6.0) and the final reaction mixture was $330 \mu \mathrm{l}$. In each well of a ninety-six-well plate $300 \mu \mathrm{l}$ of a $100 \mu \mathrm{g} / \mathrm{ml}$ LDL solution were added. The reaction was started by the addition of $\mathrm{CuCl}_{2}$ (final concentration $20 \mu \mathrm{mol} / \mathrm{l}$ ). The kinetics of oxidation was monitored by recording the absorption every $3 \mathrm{~min}$ for $\leq 6 \mathrm{~h}$ at $37^{\circ} \mathrm{C}$. All reaction mixtures were prepared in triplicate. For quantification, the oxidation kinetics was analysed on the basis of the oxidation lag phase which was defined as the interval between the initiation of the oxidation and the intercept of the tangent for the slope of the absorbance curve during the propagation phase. Intra- and inter-assay variations were less than 5 and $8 \%$, respectively.

\section{Methods of analyses in peripheral blood mononuclear cells}

Isolation of peripheral blood mononuclear cells. Peripheral blood mononuclear cells (PBMC) were isolated by density gradient centrifugation at $400 \mathrm{~g}$ for $20 \mathrm{~min}$ at $20^{\circ} \mathrm{C}$, and the cells were counted using a Coulter Counter Z2 (Beckman Coulter, Krefeld, Germany). Autologous serum from each subject for the culture of PBMC was heat-inactivated for $30 \mathrm{~min}$ at $56^{\circ} \mathrm{C}$.

Quantification of cytokine secretion. PBMC were cultured at $1 \times 10^{9}$ cells/ 1 in Roswell Park Memorial Institute (RPMI) medium containing $10 \%$ autologous serum $+1 \%$ penicillin/ streptomycin and were stimulated by a mixture of $2.5 \mathrm{mg}$ concanavalin $\mathrm{A} / \mathrm{l}$ and $1 \mu \mathrm{g}$ lipopolysaccharide (Escherichia coli 0111:B4)/1 for $24 \mathrm{~h}$ at $37^{\circ} \mathrm{C}$ to measure the production of the $\mathrm{T}$ helper 1 and $\mathrm{T}$ helper 2 cytokines GM-CSF, interferon- $\gamma$, 
IL-2, IL-4, IL-5, IL-10, IL-12 (p70), IL-13 and TNF- $\alpha$ by a bead-based multiplex cytokine assay. Cell-free supernatant fraction fluid was collected and stored at $-80^{\circ} \mathrm{C}$ until analysis. The multiplex assay was performed according to the manufacturer's instructions (Bio-Plex Human Cytokine Th1/ Th2 Panel; Bio-Rad Laboratories, Munich, Germany). Measurements and data analyses with five-parametric-curve fitting were performed on the Bio-Plex System in combination with the Bio-Plex Manager software version 4.1 (BioRad Laboratories).

Quantification of natural killer cells. The percentage of $\mathrm{CD}^{-}{ }^{-} \mathrm{CD} 16^{+} \mathrm{CD} 6^{+}$natural killer (NK) cells was measured by flow cytometry (FACSCalibur; BectonDickinson, Heidelberg, Germany) as described earlier ${ }^{(24)}$. Antibodies to quantify NK cells were purchased from Becton Dickinson (Simultest).

Peripheral blood mononuclear cell proliferation and lytic activiy of natural killer cells. Proliferation of PBMC and the NK cell activity of PBMC were determined as described previously $^{(23,29)}$.

Single cell microgel electrophoresis assay (comet assay). DNA damage was measured by the single cell microgel electrophoresis assay (comet assay) described previously ${ }^{(18)}$.

Carotenoid concentration in peripheral blood mononuclear cells. For analysis of the carotenoid concentration in PBMC $10 \times 10^{6}$ cells were used. Cells were lysed in an ultrasonic bath. Extraction and HPLC analysis were conducted in accordance with the procedure for plasma.

\section{Statistical analysis}

All statistical calculations were performed using the StatView program (version 5.0; SAS Institute, Inc., Cary, NC, USA). Results are reported as mean values and standard deviations. Differences between the mean values of the $\alpha$-carotene, $\beta$-carotene and lutein concentrations and the antioxidant activity in carrots were statistically analysed using the unpaired Student's $t$ test. Changes between the baseline (day 0) and the following time points among the three treatment groups were tested for significance by repeated-measures ANOVA and the TukeyKramer post hoc test. Plasma $\alpha$-carotene concentrations were transformed twice logarithmically since the equal variance and normal assumptions of ANOVA were rejected by the Forsythe-Brown test. Differences were considered significant at $P<0 \cdot 05$.

\section{Results}

\section{Carotenoid content and antioxidant activity in carrots}

The total carotenoid content (sum of $\alpha$-carotene, $\beta$-carotene and lutein) in organically and conventionally grown blanched carrots was 121 (SD 7) and 116 (SD 13) $\mu \mathrm{g} / \mathrm{g}$ with a major contribution from $\beta$-carotene (Fig. 1). The results of the lipophilic antioxidant capacity of blanched carrots are listed in Table 1. No statistically significant difference was observed.

\section{Dry matter content of carrots}

The DM content of the analysed carrots ranged between $11 \cdot 1$ and $18.4 \%$. No significant differences were observed between

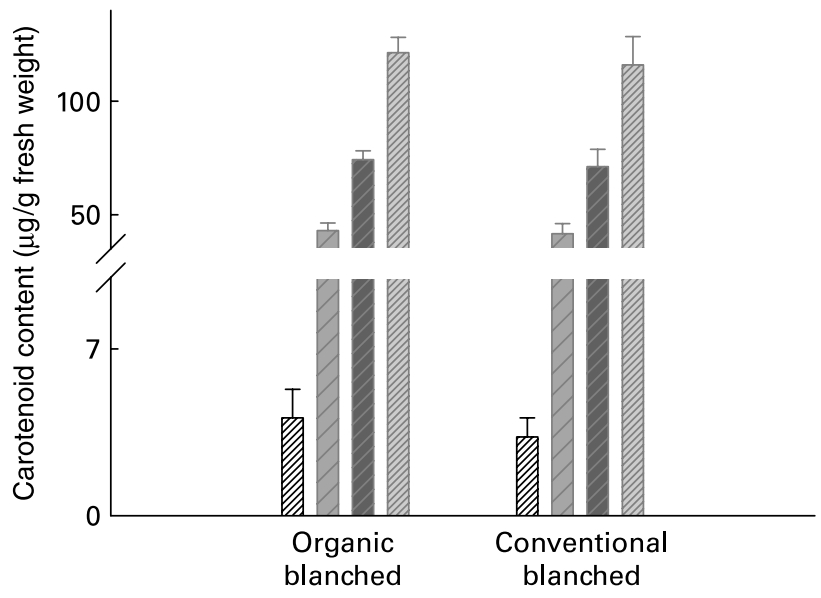

Fig. 1. Carotenoid content of blanched carrots (Daucus carota ssp. sativus, variety Narbonne). ( $\square$ ), Lutein; $(\square), \alpha$-carotene; $(\square), \beta$-carotene; $(\mathbb{Z})$, total carotenoids. Total carotenoids was calculated as the sum of the carotenoids lutein, $\alpha$-carotene and $\beta$-carotene. Values are means $(n 5)$, with standard deviations represented by vertical bars. There were no significant differences (unpaired Student's $t$ test).

the organically (13.3 (SD 2.9) \%) and conventionally (13.7 (SD 2.6) \%) produced carrots.

\section{Intervention study}

All thirty-six volunteers completed the study. The parameters age, BMI, blood glucose, lipid profile, as well as plasma vitamins $C$ and $E$ at day 0 are summarised in Table 2. No significant differences were seen between the three groups. Intervention with carrots did not affect plasma glucose, uric acid, TAG, cholesterol, vitamin $\mathrm{C}$ and vitamin $\mathrm{E}$ significantly (data not shown).

In Figs. 2 (a) and (b) the changes in plasma $\alpha$ - and $\beta$-carotene concentrations are shown. After consumption of organically as well as conventionally produced carrots plasma $\alpha$ - and $\beta$-carotene in both intervention groups increased significantly compared with the control group. While plasma lutein increased significantly in the organic group, no differences were observed between groups for zeaxanthin and $\beta$-cryptoxanthin (data not shown). The lycopene concentration decreased in both intervention groups (data not shown). There were no significant differences between the organic and conventional groups in any of the carotenoids analysed.

Table 1. Lipophilic antioxidant activity of blanched carrots (Daucus carota ssp. sativus, variety Narbonne)*

(Mean values and standard deviations for five different samples)

\begin{tabular}{llr}
\hline & \multicolumn{2}{c}{$\begin{array}{c}\text { Antioxidant capacity ( } \mu \mathrm{mol} \text { Trolox } \\
\text { equivalents/g fresh weight) }\end{array}$} \\
\cline { 2 - 3 } & Mean & SD \\
\hline Organic & 0.43 & 0.08 \\
Conventional & 0.32 & 0.07 \\
\hline
\end{tabular}

*There were no significant differences (unpaired Student's $t$ test). 
Table 2. Characteristics of study participants at day 0 of the intervention period*

(Mean values and standard deviations)

\begin{tabular}{|c|c|c|c|c|c|c|}
\hline & \multicolumn{2}{|c|}{$\begin{array}{l}\text { Organic group } \\
\quad(n 12)\end{array}$} & \multicolumn{2}{|c|}{$\begin{array}{l}\text { Conventional } \\
\text { group }(n 12)\end{array}$} & \multicolumn{2}{|c|}{$\begin{array}{c}\text { Control group } \\
\quad(n 12)\end{array}$} \\
\hline & Mean & SD & Mean & SD & Mean & SD \\
\hline Age (years) & 35.7 & $10 \cdot 2$ & 31.5 & 7.7 & $29 \cdot 3$ & 7.9 \\
\hline BMI $\left(\mathrm{kg} / \mathrm{m}^{2}\right)$ & 23.9 & $2 \cdot 2$ & 24.5 & 1.9 & 22.9 & 1.8 \\
\hline \multicolumn{7}{|c|}{ Blood parameters $(\mathrm{mg} / \mathrm{l})$} \\
\hline TAG & 995 & 347 & 904 & 245 & 909 & 379 \\
\hline Cholesterol & 1882 & 310 & 1855 & 433 & 1590 & 419 \\
\hline Glucose & 872 & 65 & 833 & 49 & 807 & 69 \\
\hline Uric acid & 56 & 10 & 53 & 10 & 55 & 13 \\
\hline \multicolumn{7}{|l|}{ Vitamins $(\mu \mathrm{mol} / \mathrm{l})$} \\
\hline$\alpha$-Tocopherol & $20 \cdot 0$ & 6.8 & 18.9 & 2.5 & $18 \cdot 8$ & $4 \cdot 1$ \\
\hline Vitamin C & 79.6 & $12 \cdot 1$ & 75.9 & 20.9 & $75 \cdot 2$ & $18 \cdot 7$ \\
\hline
\end{tabular}

*No significant differences were observed between the groups (ANOVA).

The antioxidant status at day 0 and day 14 of the intervention period is shown in Tables 3 and 4. Carrot consumption had no effect on the antioxidant status in plasma, as determined by the FRAP, TEAC and ORAC assays. Additionally, no effect on the ex vivo LDL oxidation was found.
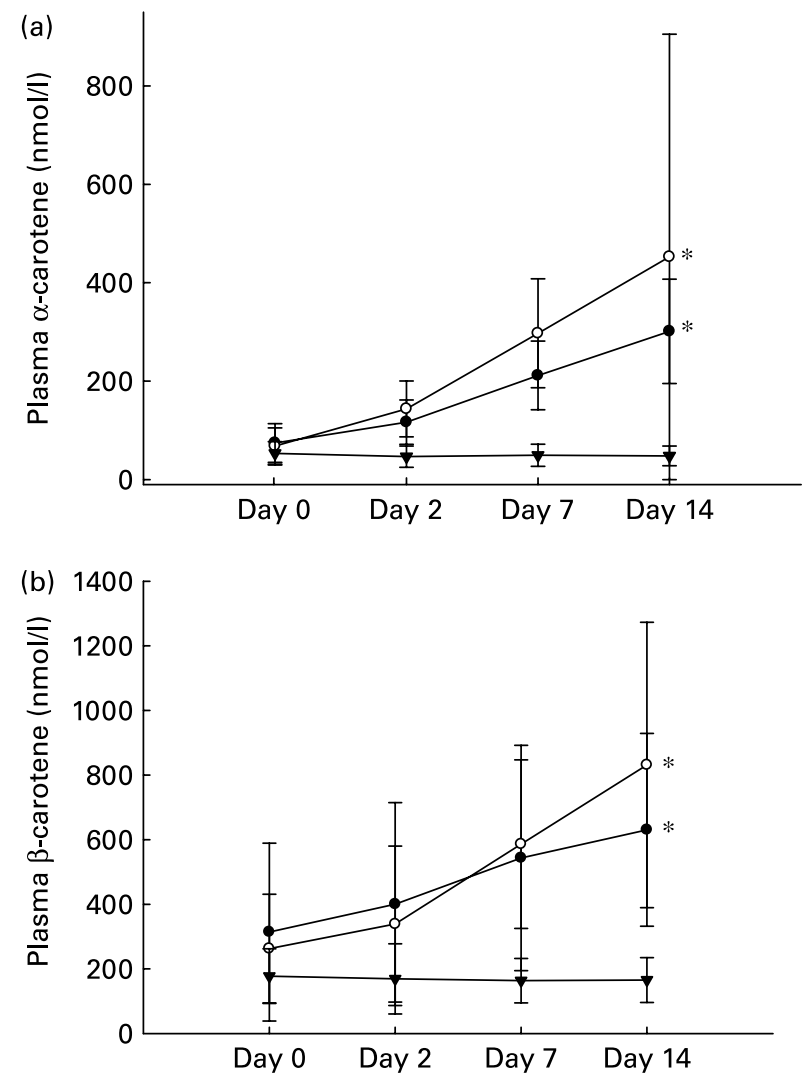

Fig. 2. Changes in $\alpha$-carotene (a) and $\beta$-carotene (b) concentrations during the intervention period in the organic carrot-fed group (--) , the conventionally grown carrot-fed group (-O-) and the control group $(-\nabla-)$. Values are means ( $n$ 12), with standard deviations represented by vertical bars. * Mean value was significantly different from that at day $0(P<0.001$; repeatedmeasures ANOVA; Tukey-Kramer post hoc test).

\section{Carotenoid concentrations in peripheral blood} mononuclear cells

Carrot intake for $14 \mathrm{~d}$ did not significantly increase the $\alpha$-carotene, $\beta$-carotene, lutein, zeaxanthin, $\beta$-cryptoxanthin or lycopene concentrations in the PBMC of the volunteers (Table 5). Furthermore, no statistically significant differences between the groups were observed.

\section{Immune parameters}

No significant changes were observed with regard to PBMC proliferation, percentages of NK cells, lytic activity of NK cells and cytokine secretion at day 0 and after $14 \mathrm{~d}$ intervention with carrots (data not shown).

\section{DNA damage in peripheral blood mononuclear cells}

There were no statistically significant differences between the three groups at day 0 and after intervention (day 14) for levels of endogenous DNA damage (strand breaks, endonuclease III- and Fpg protein-sensitive sites), nor in the capacity to protect DNA against damage caused by $\mathrm{H}_{2} \mathrm{O}_{2}$ or iron chloride (Tables 3 and 4).

\section{Discussion}

Data on the influence of the farming system on phytochemical content, their bioavailability and physiological effects are scarce. Therefore, the aim of the present study was to evaluate the bioavailability of carotenoids from blanched carrots produced under defined conventional and organic conditions. Furthermore, the antioxidant status (FRAP, TEAC and ORAC assays, LDL lag-time test and DNA strand breaks) and immune parameters (for example, percentages and lytic activity of NK cells) were investigated in subjects consuming carrots from the two production systems.

The carotenoid levels and the antioxidant capacity of carrots (variety Narbonne) in the present study were similar to those previously reported ${ }^{(9)}$. Additionally, no significant differences were found between the carotenoid concentration of organically and conventionally produced carrots in other studies $^{(13,30)}$, confirming our own observations. The present data indicate no differences between organically and conventionally produced carrots in antioxidant capacity. Therefore, other antioxidant substances in carrots (for example, polyphenols, vitamins) may also not be affected by the different agricultural systems ${ }^{(26,31,32)}$.

During the 2-week intervention period, the volunteers ingested 24.3 (SD 1.4) mg (organic group) or 23.2 (SD 2.5) mg (conventional group) total carotenoids per $\mathrm{d}$. These carotenoid intakes resulted in similar plasma concentrations of about $700 \mathrm{nmol} / 1$ for $\beta$-carotene, $350 \mathrm{nmol} / 1$ for $\alpha$-carotene and $150 \mathrm{nmol} / 1$ for lutein. The total carotenoid plasma concentrations at day 0 as well as the increase after carrot consumption for 2 weeks are in agreement with previous reports ${ }^{(33,34)}$. The consumption of organic and conventional blanched carrots for 2 weeks significantly increased the plasma $\alpha$-carotene and $\beta$-carotene concentrations compared with the control 
Table 3. Parameters of the antioxidant status of the subjects at day $0^{*}$ (Mean values and standard deviations)

\begin{tabular}{|c|c|c|c|c|c|c|}
\hline & \multicolumn{6}{|c|}{ Day 0} \\
\hline & \multicolumn{2}{|c|}{$\begin{array}{l}\text { Organic group } \\
\quad(n 12)\end{array}$} & \multicolumn{2}{|c|}{$\begin{array}{c}\text { Conventional group } \\
(n 12)\end{array}$} & \multicolumn{2}{|c|}{$\begin{array}{c}\text { Control group } \\
\quad(n 12)\end{array}$} \\
\hline & Mean & SD & Mean & SD & Mean & SD \\
\hline $\operatorname{FRAP}\left(\mu \mathrm{mol} \mathrm{Fe} \mathrm{F}^{2+} / \mathrm{l}\right)$ & 925 & 139 & 921 & 160 & 968 & 173 \\
\hline ORAC ( $\mu \mathrm{mol}$ Trolox equivalents/l) & 11729 & 1300 & 12872 & 1682 & 12095 & 1596 \\
\hline TEAC ( $\mu \mathrm{mol}$ Trolox equivalents $/ \mathrm{l})$ & 2636 & 26 & 2615 & 26 & 2634 & 35 \\
\hline Lag time (min) & 116 & 47 & 106 & 26 & 96 & 44 \\
\hline DNA strand breaks (tail moment) & 1.9 & 0.8 & $2 \cdot 2$ & 1.4 & 1.5 & 0.7 \\
\hline
\end{tabular}

FRAP, ferric-reducing ability of plasma; ORAC, oxygen radical absorbance capacity; TEAC, Trolox equivalent antioxidative capacity.

${ }^{*}$ No significant differences were observed between the groups (ANOVA).

group. The intervention with carrots had no effect on the zeaxanthin and $\beta$-cryptoxanthin concentrations. This is reasonable because they are not contained in carrots. The compliance with the low-carotenoid diet of the volunteers was good, as reflected by the low plasma concentrations of the control group. The lycopene concentration decreased in both intervention groups, presumably because of the low intake of tomatoes and tomato products.

To date, no human intervention study has been conducted to analyse the bioavailability of carrot carotenoids (lutein, $\alpha$-carotene and $\beta$-carotene) from organic and conventional agricultural systems. Caris-Veyrat et al. ${ }^{(5)}$ conducted a human intervention study to investigate the bioavailability of carotenoids (lycopene, $\beta$-carotene) from organically and conventionally produced tomato purée after a consumption period of 3 weeks. The authors report that the carotenoid concentration in human plasma increased significantly. However, no differences were observed between the organic and conventional groups $^{(5)}$. This is in agreement with the present results. One might speculate that the similar carotenoid content ( $\alpha$-carotene, $\beta$-carotene, lutein) in carrots or tomatoes was responsible for the comparable bioavailability of carotenoids. Therefore, the difference in the plant matrix that might be caused by the different agricultural systems may not be relevant for the bioavailability of carotenoids ${ }^{(20,21)}$.

Furthermore, possible physiological effects on human health were investigated. The plasma antioxidant capacity of the volunteers was measured using three different antioxidant assays (FRAP, ORAC and TEAC assays). The $\mathrm{Cu}^{2+}$-induced LDL oxidation (lag-time test) was used for the lipophilic antioxidant status. Oxidation of LDL and the subsequent generation of lipid hydroperoxides and other lipid peroxidation products are hypothesised to play a crucial role in the development of atherosclerosis and $\mathrm{CVD}^{(35)}$. The 2 weeks of intervention had no effect on the antioxidant status of the volunteers, despite the increase in plasma carotenoid concentration. Previous reports on the effects of carotenoids and carotenoid-rich foods on lipid peroxidation are inconsistent $^{(36)}$. The results of the present study are in agreement with our previous studies ${ }^{(23,37,38)}$. A possible explanation for the lack of an effect on the antioxidant status and LDL oxidation in the present study is that 2 weeks of intervention with blanched carrots may not be sufficient to enhance the antioxidative status and to protect the LDL against oxidation.

The immunomodulatory activity of carotenoids (namely $\beta$-carotene) has been demonstrated in several animal studies $^{(39)}$, whereas data from human intervention studies with carotenoid supplements or carotenoid-rich foods are controversial. Carotenoids are able to modulate the primary immune response and moderate the activity of redox-sensitive transcription factors, also implicated in mutagenesis and carcinogenesis $^{(40)}$. In the present study none of the analysed immune parameters after carrot consumption was modified. This finding is in line with results from our previous study dealing with the impact of carrot juice consumption on T-lymphocyte functions in healthy males where also no

Table 4. Parameters of the antioxidant status of the subjects at day $14^{*}$

(Mean values and standard deviations)

\begin{tabular}{|c|c|c|c|c|c|c|}
\hline & \multicolumn{6}{|c|}{ Day 14} \\
\hline & \multicolumn{2}{|c|}{$\begin{array}{l}\text { Organic group } \\
\qquad(n 12)\end{array}$} & \multicolumn{2}{|c|}{$\begin{array}{c}\text { Conventional group } \\
(n 12)\end{array}$} & \multicolumn{2}{|c|}{$\begin{array}{l}\text { Control group } \\
\quad(n 12)\end{array}$} \\
\hline & Mean & SD & Mean & SD & Mean & SD \\
\hline $\operatorname{FRAP}\left(\mu \mathrm{mol} \mathrm{Fe} \mathrm{F}^{2+} / \mathrm{l}\right)$ & 906 & 135 & 908 & 130 & 903 & 135 \\
\hline ORAC ( $\mu$ mol Trolox equivalents/l) & 12185 & 1075 & 12466 & 1333 & 11896 & 2134 \\
\hline TEAC ( $\mu \mathrm{mol}$ Trolox equivalents/l) & 2627 & 28 & 2601 & 32 & 2614 & 50 \\
\hline Lag time (min) & 113 & 25 & 108 & 34 & 93 & 30 \\
\hline DNA strand breaks (tail moment) & 1.3 & 0.4 & 1.8 & $1 \cdot 1$ & 1.3 & 0.4 \\
\hline
\end{tabular}

FRAP, ferric-reducing ability of plasma; ORAC, oxygen radical absorbance capacity; TEAC, Trolox equivalent antioxidative capacity

* No significant intervention effects were observed compared with day 0 (group and time $\times$ group) (repeated-measures ANOVA). 
Table 5. Carotenoid concentration of peripheral blood mononuclear cells before and after the 2-week intervention*

(Mean values and standard deviations for twelve men per group)

\begin{tabular}{|c|c|c|c|c|}
\hline & \multicolumn{4}{|c|}{ Carotenoid concentration ( $\mathrm{pg} / 10^{6}$ cells) } \\
\hline & \multicolumn{2}{|c|}{ Day 0} & \multicolumn{2}{|c|}{ Day 14} \\
\hline & Mean & SD & Mean & SD \\
\hline \multicolumn{5}{|l|}{ Lutein } \\
\hline Organic & 156 & 122 & 108 & 49 \\
\hline Conventional & 86 & 53 & 72 & 41 \\
\hline Control & 116 & 64 & 172 & 154 \\
\hline \multicolumn{5}{|l|}{$\alpha$-Carotene } \\
\hline Organic & 244 & 108 & 220 & 119 \\
\hline Conventional & 120 & 60 & 179 & 131 \\
\hline Control & 139 & 97 & 116 & 45 \\
\hline \multicolumn{5}{|l|}{$\beta$-Carotene } \\
\hline Organic & 934 & 454 & 855 & 427 \\
\hline Conventional & 553 & 267 & 657 & 461 \\
\hline Control & 502 & 293 & 477 & 185 \\
\hline \multicolumn{5}{|l|}{ Zeaxanthin } \\
\hline Organic & 89 & 74 & 74 & 73 \\
\hline Conventional & 35 & 10 & 152 & 282 \\
\hline Control & 48 & 33 & 67 & 35 \\
\hline \multicolumn{5}{|l|}{$\beta$-Cryptoxanthin } \\
\hline Organic & 292 & 266 & 220 & 157 \\
\hline Conventional & 67 & 33 & 98 & 101 \\
\hline Control & 138 & 94 & 134 & 50 \\
\hline \multicolumn{5}{|c|}{ Lycopene (all-trans + 5-cis) } \\
\hline Organic & 1073 & 368 & 924 & 470 \\
\hline Conventional & 790 & 280 & 793 & 438 \\
\hline Control & 860 & 491 & 721 & 244 \\
\hline
\end{tabular}

* No significant differences at day 0 and at day 14 were observed between groups (group, time $\times$ group) (repeated-measures ANOVA).

stimulatory effects of carrot juice consumption on immune parameters beyond baseline levels were detected ${ }^{(29)}$. However, the 2-week depletion phase where study subjects only consumed a low-carotenoid diet, similar to the 4-week depletion period in the present study, led to a reduction of T-lymphocyte functions.

An explanation for the absence of effects on immune parameters might be that the carotenoid concentration in PBMC did not increase (Table 5). Data on the carotenoid concentration in PBMC are scarce. To date only four studies have been conducted; the PBMC carotenoid concentrations measured in the present study are comparable ${ }^{(41-44)}$. In these studies $25 \mathrm{~g}$ tomato purée (containing $7 \mathrm{mg}$ lycopene and $0.3 \mathrm{mg} \beta$-carotene) and the application of $\beta$-carotene supplementations (ranging between 50 and $580 \mathrm{mg} / \mathrm{d}$ ) increased the $\beta$-carotene concentration in PBMC ${ }^{(41-44)}$. Possibly the carotenoid content in the carrots of the present study was too low to induce an increase in carotenoids in the PBMC. As Hughes outlined in his review ${ }^{(19)}$, changes in immune functions especially after supplementation with $\beta$-carotene are more marked in the elderly. Probably, immunomodulatory events could have been detected in an older collective than used in the present study with subjects aged between 19 and 54 years (median age 32 years).

In the present study the endogenous DNA strand breaks were not affected by the 2-week intervention with $200 \mathrm{~g}$ blanched carrots daily. Conversely, we reported decreased levels on endogenous DNA strand breaks in subjects who followed 2 weeks' consumption of carrot juice $(330 \mathrm{ml} /$ d) ${ }^{(37)}$. The different results might be due to the different carotenoid uptakes. In the study by Pool-Zobel et al. ${ }^{(37)}$ $38.0 \mathrm{mg}$ carotenoids/d in the form of carrot juice were ingested. In the present study the carotenoid uptake was $24.3 \mathrm{mg} / \mathrm{d}$ (organic group) and $23.2 \mathrm{mg} / \mathrm{d}$ (conventional group) in the form of blanched carrots, resulting in a $40 \%$ lower intake than in our previous study. In addition, the bioavailability of carotenoids from carrots is affected by the processing method and differences in the food matrix ${ }^{(45)}$. Heat treatment and also homogenisation of carrots improved the bioavailability of carotenoids ${ }^{(45,46)}$. This was reflected also in the increase in the plasma carotenoid concentrations. In the present study, the $\alpha$-carotene concentration increased by $81 \%$ and the $\beta$-carotene concentration by $60 \%$. In the study by Pool-Zobel et al. the $\alpha$-carotene concentration increased by $90 \%$ and the $\beta$-carotene concentrations by $79 \%{ }^{(23,37)}$. Thus, the differences in carotenoid uptake, the processing method between blanched carrots and carrot juice, and the different plasma carotenoid concentrations could explain the controversial results.

Taken together, this is the first intervention study to have assessed the bioavailability, the antioxidant status, DNA strand breaks and the effect on immune parameters of organically and conventionally grown carrots. The agricultural system had no effect on the carotenoid concentration in the carrots as well as no effect on the bioavailability of carotenoids from blanched carrots. Finally, no antioxidant, antigenotoxic or immunological effects of the carrot supplementation were observed. Whether the different farming systems affect the nutritional quality of other foods in a similar way cannot be deduced from the present study.

\section{Acknowledgements}

The present study was supported by the Federal Agency for Agriculture and Food; Bundesprogramm ökologischer Landbau (04OE027). The authors thank the volunteers of the study as well as G. Rahmann, Heinrich von Thünen-Institute, Westerau, Germany, for providing the carrots. We gratefully acknowledge the excellent technical assistance of S. Delong, S. Demirel, S. Herrmann, E. Hoch, R. Lambertz, S. Merkel and G. Schultheiss, as well as L. Korn for his statistical consultations. B. W., K. B., C. K. and A. B. developed the initial idea. A. B. was responsible for the human intervention study, C. E. R. for the HPLC analyses and S. S. for the immune parameters. B. A. S. collected and analysed the data, performed the statistical analysis, recruited and checked the volunteers and also drafted the manuscript. All co-authors participated in critically revising the manuscript. None of the authors had any conflict of interest.

\section{References}

1. Oberholtz L, Dimitri C \& Greene C (2005) Price Premiums Hold on as U.S. Organic Produce Market Expands; outlook report VGS-308-01. Washington, DC: US Department of Agriculture, Economic Research Service. http://www.ers.usda.gov/ publications/vgs/may05/vgs30801/vgs30801.pdf 
2. Chassy AW, Bui L, Renaud ENC, et al. (2006) Three-year comparison of the content of antioxidant microconstituents and several quality characteristics in organic and conventionally managed tomatoes and bell peppers. J Agric Food Chem 54, $8244-8252$.

3. Zhao X, Carey EE \& Wang W (2006) Does organic production enhance phytochemical content of fruit and vegetables? Current knowledge and prospect for research. Hort Technol 16, 449-456.

4. Perrez-Lopez AJ, Lopez-Nicolas JM, Nunez-Delicado E, et al. (2007) Effects of agriculture practices on color, carotenoids composition, and minerals contents of sweet peppers, cv Almuden. J Agric Food Chem 55, 8158-8164.

5. Caris-Veyrat C, Amiot MJ, Tyssandier V, et al. (2004) Influence of organic versus conventional agricultural practice on the antioxidant microconstituent content of tomatoes and derived purees; consequences on antioxidant plasma status in humans. J Agric Food Chem 52, 6503-6509.

6. Lombardi-Boccia G, Lucarini M, Lanzi S, et al. (2004) Nutrients and antioxidant molecules in yellow plums (Prunus domestica L.) from conventional and organic productions: a comparative study. J Agric Food Chem 52, 90-94.

7. Leclerc J, Miller ML, Joliet E, et al. (1991) Vitamin and mineral contents of carrot and celeriac grown under mineral or organic fertilization. Biol Agric Hortic 7, 339-348.

8. Mercadante AZ \& Rodriguez-Amaya DB (1991) Carotenoid composition of a leafy vegetable in relation to some agriculture variables. J Agric Food Chem 39, 1094-1097.

9. Warman PR \& Havard KA (1997) Yield, vitamin and mineral contents of organically and conventionally grown carrots and cabbage. Agric Ecosyst Environ 61, 155-162.

10. Clarke RP \& Merrow SB (1979) Nutrient composition of tomatoes homegrown under different cultural procedures. Ecol Food Nutr 1, 37-46.

11. Lester GE \& Eischen F (1996) $\beta$-Carotene content of postharvest orange-fleshed muskmelon fruit: effect of cultivar, growing location and fruit size. Plant Foods Hum Nutr 49, 191-197.

12. Schuphan W (1974) Nutritional value of crops as influenced by organic and inorganic fertilizer treatments - results of 12 years experiments with vegetables (1960-1972). Plant Foods Hum Nutr 23, 333-358.

13. Bourn D \& Prescott J (2002) A comparison of the nutritional value, sensory qualities, and food safety of organically and conventionally produced foods. Crit Rev Food Sci Nutr 42, 1-34.

14. Haker FR (2004) Organic food claims cannot be substantiated through testing of samples in the marketplace: a horticulturalist's opinion. Food Qual Pref 15, 91-95.

15. Grinder-Pedersen L, Rasmussen SE, Bugel S, et al. (2003) Effect of diets based on foods from conventional versus organic production on intake and excretion of flavonoids and markers of antioxidative defense in humans. J Agric Food Chem 51, $5671-5676$

16. Di Renzo L, Di Pierro D, Bigioni M, et al. (2007) Is antioxidant plasma status in humans a consequence of the antioxidant food content influence? Eur Rev Med Pharmacol Sci 11, 185-192.

17. Akcay YD, Yildirim HK, Guvenc U, et al. (2004) The effects of consumption of organic and nonorganic red wine on low-density lipoprotein oxidation and antioxidant capacity in humans. Nutr Res 24, 541-554.

18. Briviba K, Stracke BA, Rüfer CE, et al. (2007) Effect of consumption of organically and conventionally produced apples on antioxidant activity and DNA damage in humans. J Agric Food Chem 55, 7716-7721.

19. Hughes DA (2001) Dietary carotenoids and human immune function. Nutrition 17, 823-827.

20. Fjelkner-Modig S, Bengtsson H, Stegmark R, et al. (2000) The influence of organic and integrated production on nutritional, sensory and agricultural aspects of vegetable raw materials for food production. Acta Agric Scand 50, 1-3.

21. Beckmann EO \& Pestemer W (1975) The influence of herbicide treatment on yield and composition of carrots with different organic manuring. Landwirtsch Forsch 28, 41-51.

22. Re R, Pellegrini N, Proteggente A, et al. (1999) Antioxidant activity applying an improved ABTS radical cation decolorization assay. Free Radical Biol Med 26, 1231-1237.

23. Briviba K, Schnäbele K, Rechkemmer G, et al. (2004) Supplementation of a diet low in carotenoids with tomato or carrot juice does not affect lipid peroxidation in plasma and feces of healthy men. $J$ Nutr 134, 1081-1083.

24. Watzl B, Kulling SE, Möseneder J, et al. (2005) A 4-wk intervention with high intake of carotenoid-rich vegetables and fruit reduces plasma $\mathrm{C}$-reactive protein in healthy, nonsmoking men. Am J Clin Nutr 82, 1052-1058.

25. Benzie IFF \& Strain JJ (1999) Ferric reducing antioxidant power assay: direct measure of total antioxidant activity of biological fluids and modified version for simultaneous measurement of total antioxidant power and ascorbic acid concentration. Methods Enzymol 299, 15-27.

26. Cao G \& Prior RL (1999) Anthocyanins are detected in human plasma after oral administration of an elderberry extract. Clin Chem 45, 574-576.

27. Kleinveld HA, Hak-Lemmers HL, Stalenhoef AF, et al. (1992) Improved measurement of low-density-lipoprotein susceptibility to copper-induced oxidation: application of a short procedure for isolating low-density lipoprotein. Clin Chem 38, 2066-2072.

28. Esterbauer H, Striegl G, Puhl H, et al. (1989) Continuous monitoring of in vitro oxidation of human low density lipoprotein. Free Radic Res Commun 6, 67-75.

29. Watzl B, Bub A, Brandstetter BR, et al. (1999) Modulation of human T-lymphocyte functions by the consumption of carotenoid-rich vegetables. Br J Nutr 82, 383-389.

30. Woese K, Lange D, Boess C, et al. (1997) A comparison of organically and conventionally grown foods - results of a review of the relevant literature. J Sci Food Agric 74, $281-293$

31. Ziegler RG (1991) Vegetables, fruits, and carotenoids and the risk of cancer. Am J Clin Nutr 53, 251-259.

32. Miller NJ, Sampson J, Candeias LP, et al. (1996) Antioxidant activities of carotenes and xanthophylls. FEBS Lett 384, 240-242.

33. Müller H, Bub A, Watzl B, et al. (1999) Plasma concentrations of carotenoids in healthy volunteers after intervention with carotenoid-rich foods. Eur J Nutr 38, 35-44.

34. Briviba K, Kulling SE, Möseneder J, et al. (2004) Effects of supplementing a low-carotenoid diet with a tomato extract for 2 weeks on endogenous levels of DNA single strand breaks and immune functions in healthy non-smokers and smokers. Carcinogenesis 25, 2373-2378.

35. Diaz MN, Frei B, Vita JA, et al. (1997) Antioxidants and atherosclerotic heart disease. $N$ Engl J Med 337, 408-416.

36. Krinsky NI (2001) Carotenoids as antioxidants. Nutrition 17, 815-817.

37. Pool-Zobel BL, Bub A, Muller H, et al. (1997) Consumption of vegetables reduces genetic damage in humans: first results of a human intervention trial with carotenoid-rich foods. Carcinogenesis 18, 1847-1850.

38. Bub A, Watzl B, Abrahamse L, et al. (2000) Moderate intervention with carotenoid-rich vegetable products reduces lipid peroxidation in men. J Nutr 130, 2200-2206.

39. Bendich A (1991) $\beta$-Carotene and the immune response. Proc Nutr Soc 50, 263-274.

40. Chew BP \& Park JS (2004) Carotenoid action on the immune response. J Nutr 134, 257-261. 
41. Porrini M \& Riso P (2000) Lymphocyte lycopene concentration and DNA protection from oxidative damage is increased in women after a short period of tomato consumption. J Nutr 130, 189-192.

42. Santos MS, Meydani SN, Leka L, et al. (1996) Natural killer cell activity in elderly men is enhanced by $\beta$-carotene supplementation. Am J Clin Nutr 64, 772-777.

43. Fotouhi N, Meydani M, Santos MS, et al. (1996) Carotenoid and tocopherol concentrations in plasma, peripheral blood mononuclear cells, and red blood cells after long-term $\beta$-carotene supplementation in men. Am J Clin Nutr 63, 553-558.
44. Murata T, Tamai H, Morinobu T, et al. (1992) Determination of $\beta$-carotene in plasma, blood cells and buccal mucosa by electrochemical detection. Lipids 27, 840-843.

45. Bryant JD, McCord JD, Unlu LK, et al. (1992) Isolation and partial characterization of $\alpha$ - and $\beta$-carotene-containing carotenoprotein from carrots (Daucus carota L.) root chromoplasts. $J$ Agric Food Chem 40, 545-549.

46. Hedren E, Diaz V \& Svanberg U (2002) Estimation of carotenoid accessibility from carrots determined by an in vitro digestion method. Eur J Clin Nutr 56, 425-430. 